\title{
CONDICIÓN JURÍDICA DEL ESTRECHO DE MAGALLANES
}

\section{LEGAL CONDITION OF THE STRAIT OF MAGELLAN}

\section{JOHN RANSON GARCÍA*}

RESUMEN: Los temas abordados en este estudio pretenden dilucidar la interrogante sobre cuál es el ordenamiento jurídico que rige al Estrecho de Magallanes, en relación con los Tratados de Límites de 1881 y de Paz y Amistad de 1984, suscritos por las Repúblicas de Chile y Argentina, y la Convención de Naciones Unidas sobre el Derecho del Mar, unido lo anterior, a los problemas que, eventualmente, se pudieren derivar tomando en consideración que Chile en el año 1997 ratificó la citada Convención.

Palabras clave: Estrechos, Paso Inocente, Paso en Tránsito.

ABSTRACT: The matters brought up in this study will help clear up the question regarding which is the judicial standard that applies at the Strait of Magellan in relation to the Treaties of Boundaries of 1881 and those of "Peace and Friendship" of 1984, signed by the Republic of Chile and Argentina, and the United Nations Convention on the Law of the Sea, in accordance as follows, on problems which, eventually, outcome might lead to the fact that Chile in the year 1997 ratified the above mentioned Convention.

Key words: Straits, Innocent Passage, Transit Passage.

\section{INTRODUCCIÓN}

Los Tratados celebrados por las Repúblicas de Chile y Argentina en los años 1881 y 1984, fijaron definitivamente el dominio del Estrecho de Magallanes para Chile; sin embargo, dicho dominio quedó sujeto a ciertas limitaciones relativas a la libre navegación por el Estrecho, a su neutralización, y a la prohibición de fortificar sus costas.

Para comenzar el análisis sobre la situación jurídica del Estrecho de Magallanes, es necesario efectuar previamente una breve descripción histórica que sitúe en su perspectiva exacta el Tratado de Límites con Argentina del año 1881. Este Acuerdo establece un régimen especial, cuyos alcances y sentidos no pueden entenderse debidamente si no nos remontamos a la génesis de su texto, de forma tal de comprender a cabalidad la importancia que este reviste, ya que es el único estrecho que posee nuestro país, pues el resto de sus vías de aguas internas son canales.

\footnotetext{
* Profesor de Derecho Internacional Público, Universidad Central de Chile y Profesor adjunto de Derecho Internaccional Público, Universidad de los Andes

** Licenciado en Ciencias Jurídicas y Sociales en la Pontificia Universidad Católica de Valparaíso, Magíster en Derecho Universidad de Chile, Becario del Programa de Doctorado, Universidad de los Andes, Chile. Correo electrónico:johnp.ranson@gmail.com
} 
Es así como en el año 1842, Manuel Bulnes, elegido Presidente de la República de Chile, se ocupó desde los primeros meses de su gobierno del Estrecho de Magallanes, resolviendo a principios de ese año que ante todo debía tomarse posesión real y efectiva de dicha vía de agua, confiando el manejo de tan importante empresa a su Ministro de Guerra y Marina, don Manuel Montt, y nombrando como Intendente de Chiloé a Domingo Espiñeira, a quien le correspondió la tarea de organizar una expedición cuyo objetivo sería tomar posesión del Estrecho de Magallanes y sus territorios.

Los aprestos tardaron poco más de un año hasta que con fecha 22 de mayo de 1843, zarpa de Chiloé a bordo de la corbeta Ancud, el capitán de Fragata Juan Williams, izando la bandera chilena en las orillas del Estrecho el día 21 de septiembre del mismo año, sobre Punta Santa Ana, costa patagónica, iniciando en seguida la construcción del Fuerte Bulnes que fue inaugurado en diciembre de 1843 .

Cuatro años después, el 15 de diciembre de 1847, el general argentino Juan Manuel de Rosas reclamó de este hecho así como de la construcción del Fuerte Bulnes, argumentando que este se había levantado en territorio argentino puesto que en su opinión, todo el Estrecho le pertenecía a dicho país.

Surge así una controversia limítrofe entre Chile y Argentina, respecto de la cual el Presidente Bulnes y sus sucesores, los Presidentes Montt; Pérez; Errázuriz y Pinto, defendieron con firmeza el derecho de nuestro país a todo el Estrecho.

En esta controversia, algunos ministros de Relaciones Exteriores de Chile desarrollaron acciones sobresalientes, es el caso de Adolfo Ibáñez, quien entre 1872 y 1873, apoyado en los estudios jurídicos de Miguel Luis Amunátegui, polemizó brillantemente con el plenipotenciario argentino Félix Frías, y tras demostrar que los títulos chilenos eran irredargüibles escribió -como nos recuerda el capellán Enrique Pascal García-Huidobro- lo siguiente: "La Constitución, al determinar los límites de Chile, no lo hizo de una manera taxativa, ni dijo que aquellos eran los únicos que tenía la República. Por el contrario, extendiendo esos límites hasta el Cabo de Hornos, se ve que no llegando hasta ese punto la Cordillera de los Andes, que se da por límite oriental, es forzoso convenir en que donde dicha cordillera no existe, el límite oriental no puede ser otro que el Océano Atlántico"1.

Asimismo, al canciller José Alfonso, durante la Presidencia de Aníbal Pinto, le correspondió rechazar la transacción que el ministro Bernardo de Irigoyen propuso en el año 1876, la cual llevaba el límite hasta Monte Dinero, a 15 kilómetros de la boca oriental del Estrecho $^{2}$.

Sin perjuicio de lo anterior, es necesario recordar que nuestro país, el 26 de abril del año 1873, declaró soberanamente la libre navegación y la neutralización del Estrecho de

\footnotetext{
${ }^{1}$ Pascal (1987) p. 87.

2 El canciller Alfonso señalaría en carta de 18 de julio de 1876 al agente chileno en Buenos Aires, Diego Barros Arana lo siguiente: "Así la propuesta nos quita la boca oriental del Estrecho. A este respecto, la opinión del gobierno y del país es aquí unánime: Necesitamos el Estrecho en toda su extensión. El constituye nuestra puerta, y no podemos dejar la llave en poder extraño. Si el arreglo no contuviera la condición de dejarnos completamente dueños de esa vía marítima, será forzoso acceder al arbitraje, procurando estudiar algo sobre el status quo para evitar nuevas emergencias".
} 
Magallanes, siendo ratificada dicha declaración por el Gobierno de Chile en circular de la Cancillería a los gobiernos extranjeros amigos.

Este acto unilateral chileno, muestra el convencimiento que tenía nuestro país no solo respecto de la soberanía en todo el Estrecho, del cual había tomado y firmado posesión en el año 1843, sino que, convencido además de su importancia para el tráfico internacional, se había manifestado dispuesto a neutralizarlo. Tal fue la razón por la cual, ocho años más tarde, se estableciera así en el Tratado de Límites de 1881.

\section{EL ESTRECHO DE MAGALLANES EN EL TRATADO DE LÍMITES DE 1881}

La documentación existente respecto a la gestión del Tratado de Límites de 1881 con Argentina es deficiente. Las circunstancias históricas de haberse realizado dicho Tratado a través de los agentes diplomáticos norteamericanos en Santiago y en Buenos Aires, señores Thomas A. y Thomas O. Osborn, respectivamente, obligaron en vista de la carencia de relación entre ambos Estados, a recurrir al telégrafo, fruto de esta actividad son los 22 telegramas cursados entre el 25 y 27 de junio de 1881. A este respecto, es necesario dejar constancia que no se ha publicado ninguna relación de las entrevistas que cada representante norteamericano tuvo con los respectivos cancilleres, así como tampoco de las actas de lo discutido por cada país en sus más altos niveles antes de aprobarse la fórmula del ministro de Relaciones Exteriores Bernardo de Irigoyen y del agente chileno en Buenos Aires, don Diego Barros Arana, que con algunas modificaciones constituyó el texto definitivo del Tratado.

El Tratado de Límites fue firmado en Buenos Aires, el 23 de julio de 1881, por el cónsul chileno en Buenos Aires, Francisco de Borja Echeverría, y por el ministro argentino, Bernardo de Irigoyen, siendo publicado en el Diario Oficial No 1.369, de fecha 28 de octubre de 1881. Este Tratado viene a ser la primera y más importante delimitación de fronteras existentes entre la República de Chile y la República Argentina y puso término a la controversia que en 1847 suscitó Argentina por la soberanía de Chile en el Estrecho de Magallanes. Por ese Tratado, llamado también transacción, Chile abandona a perpetuidad todo tipo de pretensiones territoriales en la Patagonia Oriental y renuncia a su costa atlántica al norte del paralelo 52, del mismo modo que la República Argentina renunció a sus pretendidos títulos sobre el Estrecho de Magallanes y canales australes.

Por medio de este Tratado, ambos Gobiernos pensaban resolver las incertidumbres derivadas de la aplicación del uti posidetis a la definición de su frontera.

El Tratado fue ratificado, como señala don Santiago Benadava, "sin perjuicio por ambos Gobiernos, previa aprobación parlamentaria en cada país. En el Senado chileno fue aprobado por 15 votos contra 3, y en la Cámara de Diputados por 47 contra 9, salvo la estipulación sobre el Estrecho de Magallanes, que fue aprobada por 44 contra 12"3.

3 Benadava (1993) p. 50. 
De esta forma, el Tratado de Límites comprende como condición de la regla general de la frontera entre Chile y Argentina, las cumbres más elevadas de la Cordillera de los Andes que dividan las aguas pasando por entre las vertientes que se desprenden a uno y otro lado. Asimismo, se encarga de trazar una línea en sentido Oeste-Este en el paralelo 52 por lo que se dejan todas las costas del Estrecho de Magallanes en poder de Chile, quedando este estrecho neutralizado a perpetuidad. Finalmente, señala una línea de delimitación en la Tierra del Fuego, por medio de una línea recta que va por el meridiano $68^{\circ}$, 34'. Oeste, desde el Cabo Espíritu Santo hasta tocar el Canal Beagle, quedando todas las islas al sur de este canal en propiedad de Chile.

El Tratado de 1881 establece la obra de la demarcación de límites, sea por medio de coordenadas geográficas (como en el extremo sur), sea por medio de una línea que debe fijarse mediante exploraciones geográficas (como para el resto de los límites hacia el norte). Este Tratado hace abstracción completa de todos los puntos de vista históricos y se funda en los principios naturales tomados de la geografía matemática y física.

En este punto se encuentra la diferencia fundamental entre la moderna cuestión de límites, desde 1881, y la anterior que tenía en cuenta la herencia de la época colonial. Se debería suponer que la cuestión ha sido así simplificada de una manera esencial, en cuanto a que los peritos llamados a delinear los límites no tenían ya necesidad de ocuparse de la presentación de las Cédulas Reales y otros documentos históricos generalmente defectuosos o poco claros, y efectivamente esto hubiera ocurrido si el nuevo principio geográfico que debía considerar la delimitación hubiera sido expresado de una manera clara y terminante.

Desgraciadamente este no ha sido el caso ya que justamente debido a la poca claridad de la redacción del fundamento principal del Tratado, ha dado lugar a una interminable serie de nuevos conflictos.

Tres de las seis cláusulas dispositivas de este instrumento jurídico guardan relación directa con esta materia. Ellas son la segunda, la quinta y la sexta.

La transacción de 1881, que fijó un límite inconmovible entre las dos Repúblicas, destina, pues, la mitad de sus disposiciones al Estrecho y necesariamente deben ser examinadas en su conjunto para conocer lo que las Partes del Tratado estipularon.

El artículo segundo dice textualmente:

"En la parte austral del continente y al norte del Estrecho de Magallanes, el límite entre los dos países será una línea que partiendo de Punta Dungeness, se prolongue por tierra hasta Monte Dinero; de aquí continuará hacia el oeste, siguiendo las mayores elevaciones de la cadena de colinas que allí existen, hasta tocar en la altura del Monte Aymond. De este punto se prolongará la línea hasta la intersección del meridiano setenta con el paralelo cincuenta y dos de latitud, y de aquí seguirá hacia el oeste coincidiendo con este último paralelo hasta el divortia aguarum de los Andes. Los territorios que quedan al norte de dicha línea pertenecerán a la República Argentina; y a Chile los que se extiendan al sur, sin perjuicio de lo que dispone respecto de la Tierra del Fuego e islas adyacentes el artículo $3^{\circ}$ ”. 
El artículo quinto prescribe lo siguiente:

"El Estrecho de Magallanes queda neutralizado a perpetuidad y asegurada su libre navegación para las banderas de todas las naciones. En el interés de asegurar esta libertad y su neutralidad, no se construirán en las costas fortificaciones ni defensas militares que puedan contrariar ese propósito".

Finalmente, el artículo sexto señala:

"Los Gobiernos de Chile y de la República Argentina ejercerán pleno dominio y a perpetuidad sobre los territorios que respectivamente les pertenecen según el presente arreglo. Toda cuestión que, por desgracia, surgiera entre ambos países ya sea con motivo de esta transacción, ya sea por cualquier otra causa, será sometida al fallo de una Potencia amiga quedando en todo caso como límite inconmovible entre las dos Repúblicas el que se expresa en el presente arreglo”.

En consecuencia, el estudio del Estrecho de Magallanes tal como aparece en el Tratado de Límites de 1881, responde a los siguientes aspectos:

1- Dominio del Estrecho.

2- Libre navegación por el Estrecho.

3- Neutralización de sus aguas.

4- Prohibición de construir fortificaciones en sus costas.

\subsection{Dominio del Estrecho}

El Tratado del Límites de 1881 representó una transacción. Lo dice expresamente el Artículo 6 del citado acuerdo al referirse al dominio perpetuo que Chile y Argentina ejercerán "sobre los territorios que respectivamente les pertenecen según el presente arreglo" y a los problemas que puedan surgir con motivo de esta transacción”.

Asimismo, la sentencia arbitral pronunciada en el año 1977 en el caso del Canal Beagle expresó:

"Como la mayor parte de los tratados, el Tratado de Límites de 1881 constituyó un arreglo transaccional entre las pretensiones de las Partes que eran diferentes entre sí y, a menudo directamente contradictorias. Ninguna de las Partes obtuvo todo lo que deseaba, pero una y otra obtuvieron lo que deseaban mayormente, a expensa de algo que, para cada una, era respectivamente menos importante”. (párrafo 16).

Esta transacción repartió tierras, y no se refirió a la vía de agua llamada Estrecho de Magallanes sino en forma indirecta al decir que la línea divisoria entre los dos países correría "al Norte del Estrecho de Magallanes" y que los "territorios que quedan al Norte de dicha línea pertenecerán a la República de Argentina”. En forma expresa se dice que pertenecerán "a Chile los (territorios) que se extendían al Sur" de la mencionada línea divisoria. 
Puesto que la línea limítrofe así establecida quedó integramente al norte del Estrecho, cuanto se extiende al sur -salvo una parte de la Isla Grande de Tierra del Fuego y las Islas Oceánicas, que son tierra y no agua- es chileno; y puesto que al sur se encuentra todo el Estrecho, todo él queda definitivamente asentado en el dominio soberano de Chile.

En esta materia, debe concederse la prioridad, entre los pareceres argentinos, al propio autor del Tratado, el Canciller Bernardo de Irigoyen, quien era autor de la proposición de 1876 que constituyó la base sobre la cual se llegó a la transacción de 1881 .

La exposición realizada por el Canciller Irigoyen a la Cámara de Diputados de su país, efectuada durante las sesiones del 31 de agosto al 2 de septiembre del mismo año, y recogida por él en publicaciones del año 1882, que abarcan 237 páginas de texto, constituye una interpretación fidedigna, a la par que un importante alegato político jurídico para defender su transacción frente a los ataques de los diputados opositores. La razón de dichos ataques provenían del reconocimiento argentino de que el Estrecho era chileno.

En consecuencia, Irigoyen debió presentar en su discurso, como lo más importante para Argentina, la adquisición de la Patagonia, como de importancia menor la renuncia al Estrecho y como de valor máximo las limitaciones incluidas en el artículo V.

El artículo II del Tratado de 1881 lleva la frontera, al norte del Estrecho, no hasta Monte Dinero, como lo proponía Irigoyen y fuere rechazado por Alfonso, sino hasta Punta Dungeness. En tanto que el artículo III traza la frontera en la Tierra del Fuego a partir del Cabo del Espíritu Santo hacia el sur, reconociéndose por Argentina que el Estrecho de Magallanes seguiría bajo la soberanía de Chile hasta el último extremo de su boca oriental.

Sin embargo, y pese a que por el Tratado de Límites del año 1881, se estableció que todo el Estrecho de Magallanes pertenecería exclusivamente a Chile, con ambas orillas y bocas, surgieron algunas tesis argentinas sobre el dominio de la boca oriental del Estrecho de Magallanes, como la del ex canciller argentino don Estanislao Zeballos, quien planteó una curiosa pretensión al reclamar por el Decreto No 1587 de 5 de noviembre y el Decreto No 1896 de 15 de diciembre, ambos del Ministerio de Relaciones Exteriores de Chile del año 1914, los que proclamaban la neutralidad del país frente a las naciones en lucha -Primera Guerra Mundial- y se determinaba la condición de aguas jurisdiccionales para las interiores del Estrecho de Magallanes.

Por su parte, el jurista argentino Eduardo Bidau ${ }^{4}$, sostuvo la tesis de que el Estrecho de Magallanes, salvo una pequeña franja que va desde Cabo Vírgenes hasta Punta Dungeness, le pertenecía a Chile. Esta pequeña franja que le correspondía a la Argentina no constituiría, en su opinión, costa del Atlántico sino del Estrecho, y de esta forma las consecuencias que se podrían derivar serían que la República Argentina se transformaba en corribereña del Estrecho teniendo condominio sobre él, obtendría una proyección de aguas territoriales en la boca oriental y tendría el control de dicha entrada para el tráfico marítimo que vaya o venga al norte.

Por otro lado, el capitán de Navío Segundo Storni ${ }^{5}$, sostenía que de acuerdo con el Tratado de 1881, la casi totalidad de las aguas y costas del Estrecho de Magallanes perte-

\footnotetext{
${ }^{4}$ BIDAU (1924) p. 168.

${ }^{5}$ STORni (1924) p. 40.
} 
necían a Chile, en cambio a la Argentina correspondía solamente la costa entre Cabo Vírgenes y Punta Dungeness, con una longitud aproximada de 10 kilómetros, agregando que el límite del Estrecho era la línea Cabo Vírgenes-Espíritu Santo.

A este respecto, el capellán Enrique Pascal García-Huidobro, nos recuerda que "desde entonces los autores argentinos han repetido las palabras del cxapitán de Navío Storni: "casi totalidad y aproximadamente $10 \mathrm{~km}$ de longitud", apareciendo reiteradamente en los autores grandes o pequeños, como si la fuerza repetitiva de las palabras pretendiera establecer un hecho jurídico que no existió en el Tratado de 1881 "6.

En este mismo orden de ideas, el ex embajador Guillermo Lagos Carmona, cita al profesor de Derecho Internacional, de nacionalidad argentina, Daniel Antokoletz, cuando este último señala que, "el Estrecho es una faja de mar libre, cuyo dominio corresponde a todos los Estados y no corresponde en especial a ninguno", agregando que, "como el Tratado de 1881, no dice en forma expresa a quién pertenecerá el dominio y la soberanía del Estrecho de Magallanes, y en cambio declara que este será neutralizado a perpetuidad y libre su navegación para todas las banderas del mundo, puede legítimamente caber la duda de si esta vía ha sido entregada al dominio de Chile o de la Argentina en su caso, o a ninguno de estos dos países en particular, reduciéndose quizás el Tratado a estipular la soberanía de uno y otro Estado sobre las costas, en la proporción arriba señalada con la prohibición de fortificarlas" 7 .

Finalmente, es necesario dejar en claro nuevamente que, en nuestra opinión, las citadas tesis no se concilian ni con lo que los negociadores del Tratado de Límites de 1881 entendieron por el Estrecho, ni con el texto mismo acordado por ellos.

\subsection{Libre navegación POR El Estrecho}

En el año 1873, en un gesto espontáneo de soberanía, Chile había declarado la libre navegación y neutralidad del Estrecho de Magallanes, mediante una circular que nuestro Gobierno hiciera llegar al Cuerpo Diplomático, en donde se expresaba el deseo chileno de que la navegación por el Estrecho de Magallanes fuere siempre franca y libre para las embarcaciones de todo el mundo, sin pretender sujetarlas a otras contribuciones que aquellas que fueren indispensable para el sostenimiento de faros y de una inspección celosa para la completa seguridad y garantía de los navegantes.

Esta Declaración fue bien recibida por los representantes de los Gobiernos estadounidense y francés, ya que colocaba por encima de todo a los intereses generales del comercio y de la navegación.

De esta manera, y dada la circunstancia que Chile ya había declarado su intención de establecer la libre navegación y la neutralización del Estrecho desde 1873, no tuvo inconveniente en proponer una redacción que dejara en claro tal propósito. Por su parte el Gobierno argentino, que al comienzo insistía en conservar el extremo oriental del Estrecho, renunciaba a él.

\footnotetext{
${ }^{6}$ Pascal (1974) p. D-8.

7 LaGos (1980) p. 164.
} 
La verdad es que bien se pudo prescindir de esta declaración en el texto del Tratado, y si los redactores del Tratado del año 1881 la consideraron, fue con el único propósito que no se dudara de sus intenciones.

En todo caso, no se trata de una navegación como en alta mar -imposible en aguas territoriales y pertenecientes a un solo Estado- sino de una que garantice la seguridad tanto de las naves que lo atraviesen, como del país dueño de esas aguas.

Estos antecedentes bastan para definir el "status" legal que rige en la actualidad la navegación en el Estrecho. El derecho a la libre navegación es allí muy anterior al Tratado de 1881 y emana del derecho internacional.

Aun cuando el Tratado de 1881 no lo hubiera mencionado, ella habría seguido existiendo del mismo modo. De aquí que cuando Chile y Argentina declararon en el artículo $\mathrm{V}$ de dicho Tratado, refiriéndose al Estrecho, que "queda asegurada su libre navegación para las banderas de todas las naciones”, no intentaron implantar la libre navegación en el Estrecho. En ese artículo V los dos países reconocieron en forma implícita la libre navegación que regía en el Estrecho y en sus accesos, y asumieron convencionalmente, cada uno por su parte y en cuanto les concierne, la obligación legal que ya tenían de asegurarla.

Esta obligación que Chile y Argentina reafirmaron en el Tratado, es una obligación negativa o de abstención, que les compele a evitar dentro del Estrecho y en sus accesos todo lo que pudiera obstruir el libre paso a un barco de cualquier bandera. Sus respectivas posiciones geográficas señalan a uno y otro país el ámbito territorial donde tendrán que cumplir dicha obligación.

Chile, como país soberano del Estrecho, tendría que abstenerse de cuanto pudiera restringir la libre navegación dentro del mismo. Por su parte, la Argentina, que no posee costas en el Estrecho sino que las aguas del acceso oriental, debería abstenerse allí de cuanto pudiera restringir el libre tránsito de las naves que pasarán del Atlántico al Estrecho, o viceversa.

El capellán Pascal al referirse a este tema en particular expresa que, "al firmarse el Tratado de 1881, no se pensó en la libre navegación absoluta, propia de la alta mar, sino en la navegación inocente, esto es, una libertad restringida. El que la evolución posterior del Derecho Internacional Marítimo haya perfilado con mayor decisión los rasgos característicos de la libre navegación y del paso inofensivo, no autoriza a sobreponer al pensamiento jurídico de cien años atrás lo que en la actualidad resulta claramente delineado" ${ }^{\text {. }}$

De esta forma, Chile impuso la redacción del artículo V, y entendió la libre navegación orientada tanto hacia el tráfico comercial como al uso inocente del Estrecho.

El Tratado de 1881 no hace distinción en cuanto a si el beneficio que consagra el artículo V, en relación a la libre navegación, se establece tanto a favor de las naves mercantes como de las naves de guerra. Pero en las negociaciones que precedieron al Convenio definitivo, y en posteriores declaraciones que hicieron las Cancillerías, quedó establecido que la libertad del Estrecho se entendía en beneficio del comercio de todas las naciones.

A este respecto, el profesor Julio Escudero sostiene que, "Chile, nunca ha entrabado el paso de las naves de guerra por el Estrecho, pero el no ejercicio de un derecho no supo-

\footnotetext{
8 PASCAL (1987) p. 141.
} 
ne renuncia o caducidad de el", por esto, pensamos que sin contravenir principio alguno en el orden jurídico, podría Chile aún prohibir aquel paso" ${ }^{\text {. }}$.

La facultad de aplicar medidas restrictivas o prohibitivas en los estrechos comprendidos dentro de las aguas territoriales de un Estado, quedó plenamente reconocida durante la Segunda Guerra Mundial, tanto respecto de los beligerantes, como, asimismo, con respecto de los neutrales, y en nuestra opinión, en el caso específico de Chile no consta en ninguna parte que haya renunciado a la aplicación de medidas de esta naturaleza.

\subsection{Neutralización de sus aguas}

La segunda idea que contempla el artículo V en estudio, se refiere a la "neutralización” del Estrecho de Magallanes.

Jurídicamente se puede distinguir entre los vocablos "neutralidad" y "neutralización”. La neutralidad se aplica a un Estado cuando se coloca por un tratado bajo el régimen de neutralidad perpetua; en cambio la neutralización se aplica a determinada parte del territorio de un Estado, cuyas modalidades son determinadas en un tratado.

Como expone don Mateo Martinic, "El concepto 'neutralidad' en cuanto a su definición ha sido largamente discutido por diversos autores y tratadistas de derecho internacional público. Estando, como está, íntimamente ligado a la idea de conflicto, el mismo es unánimemente aceptado desde hace tiempo como la expresión del sentimiento o ánimo de 'no beligerancia' o no intervención en un conflicto" 10 .

En este punto es necesario recordar el incidente que se produjo el año 1914 con el crucero británico Carnavon, el cual practicó una visita de inspección a bordo del vapor alemán Sierra Córdoba, en circunstancias en que este se hallaba fondeado en Sung Bay, Estrecho de Magallanes, y por lo tanto en aguas jurisdiccionales chilenas. El Gobierno de Chile formuló la correspondiente protesta y reclamación, conforme a los usos internacionales.

En torno a este tipo de eventualidades el profesor Escudero señala que: "Si el Estrecho de Magallanes fue reputado neutral en la última guerra (Primera Guerra Mundial), no fue porque los beligerante se sintieran obligados a la cláusula V del Tratado de 23 de julio de 1881, sino porque habiendo el Gobierno de Chile declarado su condición de neutral y, perteneciéndole la jurisdicción sobre todas las aguas, según hemos expuesto antes, este hecho convertía esas aguas en aguas igualmente neutrales"11.

Efectivamente, con fecha 15 de diciembre de 1914, el Ministerio de Relaciones Exteriores, Culto y Colonización dictó el Decreto № 1.896 en el que se declara que debían "considerarse como mar jurisdiccional o neutral las aguas interiores del Estrecho de Magallanes y de los canales australes aún en las partes que disten más de tres millas de una u otra orilla”.

Al dictar dicho Decreto, se consideró por el Ministerio de Relaciones Exteriores, Culto y Colonización, que tanto el Estrecho de Magallanes como los canales australes se

\footnotetext{
${ }^{9}$ Escudero (1927) p. 57.

${ }^{10}$ Martinic (1987) p. 19.

11 Escudero (1927) p. 66.
} 
encontraban dentro de los límites internacionales de Chile y formaban, por consiguiente, parte de su territorio.

Es dable recordar que la libre navegación, dentro del concepto de neutralización a que allí se hace referencia, tiene un importante antecedente ya que Chile, en el año 1873, había hecho conocer a los gobiernos amigos su intención de asegurar el tráfico mercantil por el Estrecho.

De esta forma, la neutralización tiene por finalidad que, en el eventual caso de producirse un conflicto bélico entre naciones extrañas, las aguas del Estrecho queden establecidas como de "no beligerancia", con el objeto de asegurar la libre navegación en beneficio del comercio universal.

Ahora bien, en el Tratado de Límites de 1881, no existe intervención de ningún otro Estado, aparte de los firmantes, y por esta razón tampoco existe ningún aval o contralor de la neutralización. A este respecto oportuno es dejar en claro que tal rol no le correspondería encarnarlo a la Argentina, aun cuando sea signatario del Tratado de 1881, ya que todo control debe ser expresamente señalado con un Convenio Internacional, y este no existe en favor de la República Argentina en el texto del Artículo V.

Por otra parte, tampoco se trata de un compromiso mutuo que cada país hubiera otorgado al otro, porque dicho otorgamiento o concesión debería haber sido expresamente considerado en el texto, tal como análogamente ocurre en los Acuerdos. Ni podría invocarse ninguna presunción jurídica a favor de Argentina, por el mero hecho de ser signatario del Convenio".

Por su parte el profesor Julio Escudero Guzmán agrega que, "La neutralización convenida por el Tratado Fronterizo de 23 de Julio de 1881, comporta un caso de neutralización no sujeta a 'garantía', porque no siendo dicha neutralización sino un convenio 'interpartes', que no obliga más que a dos países, en la mente de los negociadores estuvo que era en este caso improcedente. No es que olvidaran establecerla, como algunos han creído. Ello no; uno de los Tratados que se tuvo en vista al redactar esta cláusula del Convenio fue el Tratado de París de 30 de Marzo de 1856, y un punto de diferencia con la neutralización del Estrecho de Magallanes, es que, aquella fue garantizada y esta no"12.

A este respecto la profesora María Teresa Infante, analizando este punto relativo a la neutralización señala que, "Regarding the legal meaning of the neutralization principle, Abribat maintains that it does not create a neutralized territory, but only an obligation between Chile and Argentina. A perpetual neutralized territory requires the commitment of third powers, which is not the case of the 1881 treaty. This author states that the clause is only applicable to the two state parties to the 1881 treaty, in accordance with which they agree not to conduct hostilities in the strait"13.

Brüel interpreta esta cláusula -agrega la profesora Infante- "como una prohibición de todo tipo de actos hostiles que obliga a la Argentina y a Chile estando en guerra entre los dos Estados y, con terceros Estados en que uno de ellos es el beligerante. Esta opinión nos lleva a un resultado peculiar que no puede corresponder al correcto sentido de la cláu-

\footnotetext{
12 GuZMán (1927) p. 64.

13 Infante (1995) p. 182.
} 
sula, especialmente porque, debido a la naturaleza bilateral del Tratado de 1881, que no está sujeto a ninguna garantía internacional, la cláusula no intenta imponer obligaciones a terceros Estados".

Por lo tanto, sin perder de vista la opinión de los autores, a nuestro juicio, la neutralización comprende un servicio hecho al comercio de todas las naciones; asimismo pretende asegurar en tiempo de guerra el tráfico de las naves tanto de países neutrales como de países beligerantes, excepto en el caso en que Chile estuviera en guerra.

Igualmente, se pretende impedir por parte de Chile, que se ejecuten actos de guerra por terceras potencias dentro del Estrecho, y finalmente controlar, en caso de guerra en que Chile fuese o no parte, el acceso y el paso por el Estrecho en las condiciones precedentemente señaladas.

\subsection{PROHIBICIÓN DE FORTIFICAR SUS COSTAS}

Esta es otra restricción a la cual se halla sujeta la soberanía de Chile en el Estrecho de Magallanes. La restricción establecida en el Artículo V del Tratado de Límites de 1881 está condicionada de la siguiente forma:

"En el interés de asegurar esta libertad y neutralidad no se construirán en las costas fortificaciones ni defensas militares que puedan contrariar ese propósito”.

Por la redacción estipulada, la prohibición de construir fortificaciones y defensas militares, tiene únicamente un doble objetivo: el asegurar la libertad y neutralidad del Estrecho de Magallanes. Esto significa, que la citada prohibición rige solo en cuanto pueda contrariar este doble propósito.

Es así como el profesor y ex embajador don Guillermo Lagos Carmona, precisa que, "la prohibición de no construir en las costas del Estrecho fortificaciones ni defensas militares, es una simple obligación de no hacer y de carácter restrictivo, destinada únicamente a no entrabar la libre navegación comercial por esta vía de agua chilena que comunica mares libres" 14 .

El Tratado en este, como en todos los demás puntos, fue el resultado de una transacción, y así como Chile aceptó el no construir fortificaciones en las costas del Estrecho, tanto en interés de la neutralización, como, asimismo, de la libre navegación, la República Argentina, a su vez, no persistió en la exigencia de que aquella prohibición se extendiera más allá de aquellos dos únicos propósitos.

De esta forma Chile puede y debe construir las obras de indispensable defensa para la salvaguardia de las ciudades o poblaciones que existen o lleguen a existir en las costas del Estrecho. Jamás se tuvo en mente que el Tratado obligaba a Chile a quedar indefenso en el Estrecho o que lo sometía a una condición desmedrada respecto de otros países.

La profesora María Teresa Infante, señala que, "el sentido de esta disposición debe entenderse teniendo a la vista la proposición argentina y la respuesta chilena, manifestadas en los intercambios de telegramas que antecedieron inmediatamente a la firma del Tratado de 1881. De este intercambio resulta claro que no se trata de una prohibición de fortificar ni mucho menos de una obligación de desmilitarizar, sino que ella se encuentra supeditada

${ }^{14}$ Lagos (1985) p. 162. 
a asegurar el respeto a la libertad de navegación de la manera que en esa época se entendía y que podía ser más gravemente afectada. Tampoco afecta esta disposición, cuyos alcances son bastante restringidos en la práctica, al principio básico según el cual es el Estado ribereño el que tiene la competencia exclusiva para llevar a efecto actos de jurisdicción en las costas y en las aguas, suelo y subsuelo del estrecho, teniendo en consideración el respeto de la libertad de navegación conforme al régimen aplicable"15.

En consecuencia, no puede caber duda que para Chile esta constituyó una estipulación extremadamente onerosa, transformándose en una limitación excesiva, porque no solo afectó la parte oriental del Estrecho, que pretendía obtener Argentina, sino que también comprometió la parte occidental, que jamás había pretendido dicha República.

Finalmente y como ya analizáramos en el punto anterior, relativo a la neutralización de las aguas del Estrecho de Magallanes, el compromiso que contrajo nuestro país al neutralizar el Estrecho y comprometerse a no construir defensas que contrariaran dicho propósito, no lo hizo en beneficio de la República Argentina, sino que lo hizo con el objeto de asegurar la libre navegación en beneficio del comercio universal.

\section{EL TRATADO DE PAZ Y AMISTAD DE 1984}

Si bien el gran valor del Tratado suscrito en Buenos Aires en el año 1881 -el que puso término al prolongado litigio por la soberanía de los territorios australes del continente entre Chile y Argentina- fue la conservación del dominio del Estrecho de Magallanes por parte de Chile, es necesario precisar, como ya se hiciera mención, que esta atribución de dominio se hizo en una forma indirecta, toda vez que el artículo II, al definir la línea limítrofe para ambos países, señaló a continuación que los territorios situados al norte de la misma pasaban a pertenecer a la República Argentina, así como a Chile los que se extendían hacia el sur.

En relación con este tema, don Mateo Martinic en su trabajo titulado, "El Estrecho de Magallanes en el Tratado de Paz de 1984" expresa que, "sin dejar una constancia explícita, las aguas del Estrecho de Magallanes en su totalidad pasaron a integrar el patrimonio territorial chileno por estar al meridión de la indicada línea”. Agregando el autor a continuación que "la falta de una mención explícita para la atribución de las aguas, sino preocupó a ninguno de los contemporáneos del histórico acuerdo, a la larga habría de despertar incertidumbre respecto de un punto tan capital. Así lo que parecía obvió y claro para algunos, para otros constituyó materia de serias duda" 16 .

Sin embargo, en el citado Tratado Limítrofe de 1881, no se había considerado el límite en la boca oriental del Estrecho de Magallanes, entre Punta Dungeness y el Cabo del Espíritu Santo, separando los mares territoriales de Chile y Argentina.

\footnotetext{
${ }^{15}$ Infante (1983) p. 66.

${ }^{16}$ Martinic (1987) p. 106.
} 
En este orden de ideas, el capellán Enrique Pascal, en su obra titulada "Derecho Internacional Marítimo", propugnaba la tesis referida al derecho de Chile a una proyección de aguas atlánticas en la zona de la boca oriental del Estrecho, como consecuencia de la soberanía ejercida por la República de Chile sobre las costas que determinan su inicio.

Con el fin de superar los innumerables malos entendidos y definir definitivamente la frontera marítima entre ambos países, era evidente que se hacía necesario un acuerdo entre Chile y Argentina con respecto a esta materia.

A continuación estudiaremos, pues, cómo se fijó la frontera marítima del Estrecho de Magallanes en el Tratado de Paz y Amistad, suscrito en Ciudad del Vaticano el día 29 de noviembre de 1984.

La Mediación de SS. Juan Pablo II nace el día 8 de enero de 1979, fecha en la que se firmó el Acta de Montevideo, suscrita por el canciller Carlos Pastor de Argentina y el canciller Hernán Cubillos de Chile, con la presencia del cardenal Antonio Samoré, enviado papal. El Acta de Montevideo solicitaba al Sumo Pontífice que actuara como mediador en el diferendo de la Zona Austral sostenido por ambos países, provocado básicamente por el desconocimiento de la República Argentina de su compromiso de acatar el Laudo Arbitral de su Majestad Británica de mayo de 1977, que fijó la delimitación marítima del Canal Beagle.

Producto de esta mediación se suscribe en el año 1984 el Tratado de Paz y Amistad, cuyo artículo $10^{\circ}$, trata exclusivamente el asunto de la delimitación marítima de la Boca Oriental, a la que llama "Término Oriental", siendo su texto el siguiente:

Artículo 10․- "La República Argentina y la República de Chile acuerdan que en el término oriental del Estrecho de Magallanes, determinado por Punta Dungeness en el Norte y Cabo del Espíritu Santo en el Sur, el límite entre sus respectivas soberanías será la línea recta que una el "hito Ex Baliza Punta Dungeness", situado en el extremo de dicho accidente geográfico, y el "hito I Cabo del Espíritu Santo", en Tierra del Fuego".

"La línea de delimitación anteriormente descrita queda representada en la Carta No II anexa".

"La soberanía de la República Argentina y la soberanía de la República de Chile sobre el mar, suelo y subsuelo se extenderán al Oriente y Occidente de dicho límite”.

"La delimitación aquí convenida en nada altera lo establecido en el Tratado de Límites de 1881, de acuerdo con el cual el Estrecho de Magallanes está neutralizado a perpetuidad y asegurada su libre navegación para las banderas de todas las naciones en los términos que señala su artículo V".

"La República Argentina se obliga a mantener, en cualquier tiempo y circunstancias, el derecho de los buques de todas las banderas a navegar en forma expedita y sin obstáculo a través de sus aguas jurisdiccionales hacia y desde el Estrecho de Magallanes”.

De esta forma, el término de la Boca Oriental del Estrecho de Magallanes quedó determinado por una línea recta que une Punta Dungeness en el "hito Ex Baliza Punta Dungeness" y "Cabo del Espíritu Santo" (Hito I Cabo del Espíritu Santo) ${ }^{17}$.

${ }^{17}$ En este aspecto se hace necesario remitirse al párrafo segundo del número 4 de la declaración que Chile emitió al ratificar la Convención de las Naciones Unidas sobre el Derecho del Mar, de fecha 
Asimismo, y como antecedente previo a la mediación de Su Santidad el Papa Juan Pablo II, se puede mencionar que en octubre del año 1974 la Comisión Argentina de Límites había planteado la necesidad de comprobar el recorrido de la línea de frontera en los tramos comprendidos entre el Hito I y Punta Dungeness y el Hito I y el Cabo Espíritu Santo. Con fecha 26 de mayo de 1975, el delegado chileno, don José Mutis Puccio, informaba al presidente de la Comisión Chilena de Límites sobre la reposición o reemplazo del Hito I y Ex-Baliza Dungeness por Hitos Reglamentarios de hierro dejándose instrucciones a los guardafaros sobre la dirección del límite entre Hito Ex-Baliza Dungeness y la costa.

El concepto legal del Estrecho fue refutado por el gobierno de Argentina, el cual sostuvo una teoría de Estado corribereño, expresada en dos comunicaciones oficiales dirigidas a Chile en 1975 y 1976. Estas comunicaciones negaban los fundamentos legales de medidas adoptadas por Chile, para controlar la contaminación marina y la seguridad de la navegación en el Estrecho después del derrame de petróleo del supertanque "Metula" en 1974. Argentina exigió su derecho a participar en la regulación de la navegación por el Estrecho. En la segunda comunicación, de fecha 1976, Argentina reivindicó su condición de Estado ribereño de las dos costas del Estrecho.

De acuerdo a fuentes diplomáticas, las notas de Argentina, que habían sido rechazadas por Chile, fueron oficialmente retiradas con el intercambio de los instrumentos de ratificación del Tratado de Paz y Amistad del 2 de mayo de 1985. Las notas fueron retiradas en la etapa final de las negociaciones, con la ayuda del Papa Juan Pablo II, quien actuó como mediador.

En el mes de noviembre del año 1987, concluida la mediación, se constituyeron dos Subcomisiones Mixtas de la Comisión de Límites, integradas por un representante de cada país, los que trabajaron en Punta Dungeness y en Cabo del Espíritu Santo simultáneamente.

En el informe que presentó el delegado chileno, coronel Juan Luis Herrera Villena al señor presidente de la Comisión Chilena de Límites, al referirse a los trabajos efectuados en la sección I y II, señala: "La actividad a realizar era efectuar un levantamiento planimétrico a escala 1:2000 del sector Punta Dungeness y Cabo del Espíritu Santo respectivamente y determinar además, los valores angulares entre el Hito Ex-Baliza Dungeness-Hito I Cabo del Espíritu Santo y viceversa. Al determinar el trazo Hito Ex-Baliza Dungeness, origen Hito II-I al Hito I-I Cabo del Espíritu Santo, se pudo comprobar que el alero de la caseta de motor de la casa del Farero prácticamente rozaba dicho trazo, situación de la cual no se hizo mayor cuestión.

23 de junio de 1997 la cual señala, al referirse al Tratado de Paz y Amistad de 1984 lo siguiente: "En este último Tratado, en su artículo 10, Chile y Argentina acuerdan la línea de delimitación en el término oriental del Estrecho de Magallanes y convienen que esa delimitación en nada altera lo establecido en el Tratado de Límites de 1881, de acuerdo con el cual, y conforme Chile lo había declarado unilateralmente en 1873 , dicho estrecho está neutralizado a perpetuidad y asegurada su libre navegación para las banderas de todas las naciones, en los términos que señala su Artículo V. Por su parte, la República Argentina se obliga a mantener, en cualquier tiempo y circunstancia, el derecho de los buques de todas las banderas a navegar en forma expedita y sin obstáculos a través de sus aguas jurisdiccionales hacia y desde el Estrecho de Magallanes”. 
Los valores angulares, obtenidos como resultados de estos trabajos son los siguientes:

"Hito Ex-Baliza Dungeness, origen Hito II-I al Hito I-I Cabo del Espíritu Santo: $160^{a} 17^{\prime} 19$ ', 06.

Hito I-I Cabo del Espíritu Santo, origen Hito I-II al Hito Ex-Baliza Dungeness: $202^{a} 12^{\prime} 52^{\prime \prime}, 14 " 18$.

De este modo, la delimitación marítima de la Boca Oriental del Estrecho de Magallanes, constituye una línea fronteriza que fijó la soberanía del mar, suelo y subsuelo, al Oriente para la República Argentina y al Occidente para la República de Chile.

En esta materia se puede argumentar como señala Sergio Paravic Valdivia que, "Chile logró hacer desaparecer la pretensión argentina de la existencia de un "Estrecho de Magallanes Argentino" que ese país postuló en un pequeño triángulo al oriente de la línea recta Dungeness - Espíritu Santo, cercando Espíritu Santo con el Cabo Vírgenes, al reconocer Argentina que el término oriental del Estrecho de Magallanes es dicha línea recta, pero a un alto precio, pues en cambio generó la jurisdicción de Argentina sobre todas las aguas, suelos y subsuelos al oriente de la línea Dungeness - Espíritu Santo, en aguas del Atlántico"19.

Por lo tanto, al adoptar como límite la línea recta Punta Dungeness - Cabo Espíritu Santo, Chile y Argentina pasaron a colmar con sus soberanías todas las superficies marítimas que constituyen la boca del Estrecho y su salida atlántica.

La soberanía de que hablan los incisos primero y tercero del citado artículo 10 recae, según este último, sobre el "mar, el suelo y el subsuelo". El inciso tercero describe así, sin nombrarlo, el mar territorial, pues se ha referido a todos los elementos que la Convención sobre el Derecho del Mar emplea en su artículo 2 para definirlo; según este artículo, el mar territorial es una franja adyacente al territorio, donde la soberanía del Estado ribereño se extiende al mar, "así como al lecho y al subsuelo de ese mar".

Por lo demás, basta que los incisos mencionados digan que la recta Punta Dungeness - Cabo del Espíritu Santo divide "las soberanías" de las partes, para concluir que a todo lo largo de ella no puede haber sino mar territorial, pues hasta la distancia de $12 \mathrm{mi}$ llas no hay ningún otro espacio marítimo que caiga bajo la soberanía del Estado ribereño, con excepción de las aguas interiores, situación esta última que no se encontraba presente en el área del trazado acordado.

Podemos entonces concluir que Chile y Argentina afirman en el artículo 10, incisos primero y tercero, del Tratado de Paz y Amistad de 1984, que sus mares territoriales se extienden del lado que a cada uno le corresponde desde un extremo al otro de la recta Punta Dungeness - Cabo del Espíritu Santo.

${ }^{18}$ Dirección Nacional de Fronteras y Límites del Estado (DIFROL) Acta No 5 1988. Informe del delegado coronel Juan Luis Herrera Villena, al Sr. presidente de la Comisión Chilena: Ministerio de Relaciones Exteriores Cabo del Espíritu p. 98.

19 PARAVIC (1986) p. 89. 
En el inciso final del citado artículo 10, Argentina ha asumido la obligación de mantener "en cualquier tiempo y circunstancias, el derecho de los buques de todas las banderas a navegar en forma expedita y sin obstáculos a través de sus aguas jurisdiccionales, hacia y desde el Estrecho de Magallanes".

A juicio de don Mateo Martinic, "esta disposición establece una servidumbre de paso perpetua e imperturbada por parte de Argentina y en favor de terceros, en orden al uso expedito y franco hacia y desde el gran canal magallánico. Esta última mención particular ratifica una vez más, desde ahora y para siempre, que al oriente de la frontera marítima acordada solo hay aguas de jurisdicción Argentina, y al occidente, aguas de soberanía chilena" 20 .

En el inciso final del artículo 10, se alude dos veces al mar territorial de Argentina. Primero, en forma implícita, ya que no hay ningún otro espacio marítimo, aparte de su propio mar territorial -con excepción del caso no presente de las aguas interiores-, donde un Estado pueda dispensar facilidades especiales para la navegación, ya que en todos los demás hay libertad de navegación. Se alude, asimismo, al mar territorial en forma explícita, porque al referirse a sus "aguas jurisdiccionales", lo caracteriza tal como si lo hubiera nombrado.

Sin embargo, en este punto es imprescindible recordar el inciso cuarto del artículo 10 , en que las partes declaran que "la delimitación aquí convenida en nada altera lo establecido en el Tratado de 1881, de acuerdo con el cual el Estrecho de Magallanes queda neutralizado y asegurada su navegación para las banderas de todas las naciones".

Cuando las partes contratantes concordaron que en el acceso oriental del Estrecho existirían "aguas jurisdiccionales" argentinas, entendieron que el artículo V del Tratado de Límites de 1881 obligaba igualmente a la República Argentina a asegurar la libre navegación, absteniéndose de todo lo que pudiera obstruirla en su acceso oriental. De forma tal que cuando las partes afirman que "la delimitación convenida en nada altera lo establecido en el Tratado de 1881" debe entenderse que se reafirman las obligaciones que Chile y Argentina asumieron en el año 1881, para asegurar la navegación dentro del Estrecho de Magallanes y en sus accesos, tanto a favor de las mismas partes contratantes como a favor de terceros Estados, situación esta que hiciéramos presente al estudiar el punto relativo a la libre navegación por el Estrecho.

Analizando las obligaciones que contrae la Argentina en el inciso final del artículo 10, en donde se prescribe que "La República Argentina se obliga a mantener en cualquier tiempo y circunstancias el derecho...”, es necesario precisar que el término "mantener" involucra el reconocimiento de un derecho previamente existente. A su vez, dado el carácter permanente de esta obligación, ese derecho no podrá ser suspendido en caso alguno.

${ }^{20}$ Martinic (1984) p. 110. 


\section{LA CONVENCIÓN DE LAS NACIONES UNIDAS SOBRE EL DERECHO DEL MAR DE 1982}

La Convención sobre el Derecho del Mar de 1982 regula en su Parte III a los Estrechos utilizados para la navegación internacional, estableciendo el régimen de paso según los espacios marítimos que quedan comunicados por esta vía natural.

La Convención distingue entre varias categorías de estrechos. La primera categoría dice relación con aquellos en que se goza de un régimen más favorable para la navegación, comprendiendo a los estrechos que según el artículo 37 comunican una parte de alta mar o de una zona económica exclusiva con otra parte de alta mar o de una zona económica exclusiva; en estos estrechos se aplicaría a los buques extranjeros, en principio, el régimen de paso en tránsito.

Efectivamente, en el curso de la Tercera Conferencia sobre el Derecho del Mar, surgió una figura jurídica nueva relativa a los estrechos en que se aplica el "paso en tránsito", obteniendo su consagración definitiva en la Parte III de la referida Convención. En su artículo 38 (2) define la Convención que debe entenderse por paso en tránsito, señalando que es "el ejercicio, de conformidad con esta Parte, de la libertad de navegación y sobrevuelo exclusivamente para los fines del tránsito rápido e interrumpido por el estrecho entre una parte de la alta mar o de una zona económica exclusiva y otra parte de la alta mar o de una zona económica exclusiva”.

Asimismo, la citada Convención señala que el ejercicio del derecho de paso en tránsito debería efectuarse avanzando sin demora por o sobre el estrecho, absteniéndose de toda amenaza o uso de la fuerza contra la soberanía, la integridad territorial o la independencia de Estado ribereño, o en cualquier forma contraria a los principios de Derecho Internacional contenidos en la Carta de las Naciones Unidas.

Durante dicho paso no se podrán realizar actividades de estudio o investigación, sin autorización previa del Estado ribereño del estrecho y, finalmente, agrega la Convención que no existirá derecho de paso en tránsito si el estrecho está formado por una isla de un Estado ribereño del estrecho y su territorio continental y si al otro lado de la isla existe una ruta de alta mar o que pase por una zona económica exclusiva igualmente conveniente para la navegación.

Los Estados ribereños de un estrecho no obstaculizarán el paso en tránsito y darán a conocer de manera apropiada cualquier peligro que, según su conocimiento, amenace a la navegación en el estrecho o el sobrevuelo del mismo; asimismo, y según lo prescrito en el artículo 44 de la Convención, no habrá suspensión alguna del paso en tránsito.

Una segunda categoría de estrechos dice relación con aquellos en que independiente del paso en tránsito, se aplica el régimen de paso inocente, lo cual se produciría en tres casos.

El primer caso es el del artículo 36 de la Convención, el cual se refiere a los estrechos que siendo utilizados para la navegación internacional, pasa por ellos una ruta de alta mar o que atraviese una zona económica exclusiva, igualmente conveniente en lo que respecta a características hidrográficas y de navegación; en tales rutas se aplicarán las otras 
partes pertinentes de la Convención, incluidas las disposiciones relativas a la libertad de navegación y sobrevuelo.

Un segundo caso en que se aplica el régimen de paso inocente, es el que consagra la letra a) del párrafo 1 del artículo 45 de la Convención, que se refiere a los estrechos que quedan excluidos de la aplicación del régimen de paso en tránsito en virtud del párrafo 1 del artículo 38, el cual prescribe que no regirá el derecho de paso en tránsito, "cuando el estrecho esté formado por una isla de un Estado ribereño de ese estrecho y su territorio continental, y del otro lado de la isla exista una ruta de alta mar o que atraviese una zona económica exclusiva, igualmente conveniente en lo que respecta a sus características hidrográficas y de navegación” .

Finalmente, el paso inocente continúa aplicándose, igualmente, según lo dispuesto en la letra b) del párrafo 1 del artículo 45, a los estrechos utilizados para la navegación internacional que unen una parte de Alta Mar o de una Zona Económica Exclusiva y el Mar Territorial de otro Estado.

Según lo señalado en el párrafo 2 del artículo 45, no habrá suspensión alguna del paso inocente a través de tales estrechos.

En relación al régimen de paso por los estrechos, el profesor Hugo Llanos Mansilla, señala que, "el régimen jurídico de los estrechos utilizados para la navegación internacional antes de la presente Convención, era el paso inocente a través de las áreas de mar territorial aunque no podía ser suspendido. La Convención de Ginebra, de 1958, obligaba a los submarinos a navegar en la superficie y a mostrar su bandera. Además, el Estado ribereño tenía soberanía sobre la columna de aire encima del estrecho y podía prohibir el sobrevuelo de las aeronaves. Todo esto obstaculizaba los intereses de las grandes potencias, que deseaban el paso de submarinos en inmersión y la libertad de navegación y sobrevuelo para ciertos estrechos utilizados para la navegación internacional, aquellos de interés estratégico" 21 .

Sin embargo, este no era el único régimen que se aplicaba a los estrechos utilizados para la navegación internacional y, previendo esta situación, la Convención estableció en su artículo 35, ciertos casos que no serían afectados por sus disposiciones relativas a los estrechos.

De esta forma, el artículo 35.c), excluye del ámbito de la aplicación de la Parte III de la Convención a un reducido número de estrechos cuyo régimen de navegación ha sido regulado total o parcialmente por convenciones de larga data aun vigentes, reforzando así su normativa.

Las Convenciones a las que se referiría la letra c), del artículo 35 son: los Estrechos Daneses (Gran - Belt y Pequeño - Belt, entre el mar Báltico, Kattegat y el mar del Norte), cuyo paso se rige por la Convención de Copenhague, de 14 de marzo de 1857 ; el Estrecho de Magallanes (entre el Atlántico y el Pacífico), regulado por el Tratado de Límites entre Chile y Argentina, de 23 de julio de 1881, y los Estrechos Turcos (Bósforo y Dardanelos, que unen el mar Negro con el Mediterráneo), regulados en la Convención de Montreux, de 20 de julio de 1936.

${ }^{21}$ Llanos (1991) p. 291. 
Es así como en el artículo 35, letra c), de la Convención, dispone que: "Ninguna de las disposiciones de esta Parte afectará a... c) El régimen jurídico de los estrechos en los cuales el paso esté regulado total o parcialmente por convenciones internacionales de larga data y aún vigentes que se refieran específicamente a tales estrechos”.

La convención internacional de larga data y aún vigente que se refiere específicamente al Estrecho de Magallanes es el Tratado de Límites de 1881 entre Chile y Argentina, confirmado por el Tratado de Paz y Amistad de 1984.

A este respecto es necesario citar el párrafo primero del número 4 de la declaración que Chile formuló al ratificar la Convención de las Naciones Unidas sobre el Derecho del Mar, de fecha 23 de junio de $1997^{22}$, el cual expresa que: Respecto a la Parte III de la Convención, cabe señalar que conforme a su artículo 35, c), las disposiciones de esa Parte no afectan el régimen jurídico del Estrecho de Magallanes, ya que su paso está regulado por convenciones internacionales de larga data y aun vigentes que se refieren específicamente a tales estrechos, como el Tratado de Límites de 1881, régimen que se reitera, en el Tratado de Paz y Amistad de 1984”.

La obligación de libre navegación por el Estrecho de Magallanes que Chile y Argentina asumieron en el Tratado de Límites de 1881, como se explicó, es una obligación negativa o de abstención, que les compele a evitar dentro del Estrecho y sus accesos todo lo que pudiera obstruir el libre paso a un barco de cualquier bandera. Sus respectivas posiciones geográficas señalan a uno y otro país el ámbito territorial donde tendrían que cumplir dicha obligación. Chile, soberano de todo el Estrecho, tendría que abstenerse de cuanto pudiera restringir la libertad de navegación dentro del mismo. Por su parte, la Argentina, que no posee costas en el Estrecho, sino que en los accesos exteriores del mismo, sobre el Atlántico, debería abstenerse allí de cuanto pudiera restringir el libre tránsito de las naves que pasaran del Atlántico al Estrecho, o viceversa.

Sin embargo cabría preguntarse si en virtud del Tratado de Paz y Amistad de 1984, podría cambiarse la condición jurídica de las aguas a la salida Oriental del Estrecho en perjuicio de la libre navegación, incorporándolas Argentina a su soberanía al calificar dichas aguas como "aguas jurisdiccional"; o si, por otro lado, el artículo 10 del citado Tratado, tendría que ceder allí ante el derecho que por el largo uso han adquirido todas las naciones para pasar directamente del Estrecho a la alta mar y viceversa.

Este derecho, que es en el Estrecho consubstancial con la libre navegación y que mira al interés de la comunidad de las naciones, ciertamente prevalece sobre el que tienen todos los Estados para ampliar sus aguas jurisdiccionales, el cual solo mira a su interés particular. Cabe pues concluir que, aun cuando Argentina califique esas aguas como jurisdiccionales o territoriales, ello no altera el régimen de libertad de navegación establecido para el Estrecho y sus accesos.

La referencia del citado artículo 35 a "las convenciones de larga data y aún vigentes" alude sin duda a sus textos originales y exige que ellos no hayan sido modificados ni dero-

${ }^{22}$ Declaración chilena al ratificar la Convención de las Naciones Unidas sobre el Derecho del Mar, de fecha 23 de junio de 1997, Archivo del Ministerio de Relaciones Exteriores de 1997. p. 2. 
gados por las Partes, dando al mismo tiempo por hecho que no hayan podido ser modificadas o derogadas por el derecho internacional.

En consecuencia, en el caso del Estrecho de Magallanes, dicho artículo 35 excluye las normas sobre el derecho de paso en tránsito debido a la vigencia indefinida del artículo V del Tratado de Límites de 1881, aplicado hasta hoy bajo las mismas circunstancias existentes que cuando fue promulgado por las Partes. Dichas circunstancias no han variado con la entrada en vigencia del artículo 10 del Tratado de Paz y Amistad de 1984, aun cuando las aguas de la salida Oriental del Estrecho conlleven la condición de ser de "jurisdicción” argentina.

Por lo tanto, en nuestra opinión, se cumplirían a cabalidad los propósitos de la Convención, que deseaba mantener incólumes los regímenes jurídicos que habían estado en vigor durante largo tiempo en los estrechos internacionales, pues estimaba que era riesgoso tratar de mejorar lo que la experiencia a veces secular, como ocurría en el caso del Estrecho de Magallanes, había demostrado que funcionaba bien.

De esta manera, en el nuevo Derecho del Mar, se aplica al Estrecho de Magallanes el artículo V del Tratado de Límites de 1881, régimen que según lo precedentemente expuesto es, a nuestro juicio, más conveniente para Chile que el régimen de paso en tránsito que consagra la Convención de Naciones Unidas sobre el Derecho del Mar.

En este punto se hace necesario recordar que el régimen de paso en tránsito se aplica a la navegación submarina y al sobrevuelo, aspectos que no se incluyen en el régimen que regula el Estrecho de Magallanes. Aun cuando dichas libertades eventualmente se concedieran, su ejercicio sería prácticamente imposible, debido a la caprichosa estructura geográfica de los fondos marinos del Estrecho, al igual que sus angosturas y angulosas curvas, que harían muy difícil la navegación submarina o el sobrevuelo, salvo que se efectuara por minisubmarinos o helicópteros ${ }^{23}$.

Al fijarse un régimen especial y distinto al paso en tránsito y paso inocente que consagra la Convención de Naciones Unidas, Chile no renunció a tomar las medidas de seguridad que se estimen pertinentes, al igual que conservó la facultad de aplicar medidas restrictivas o prohibitivas, ya que no consta en parte alguna que Chile como país soberano hubiese renunciado a ello. Asimismo, es necesario precisar que no rige el "Paso en Tránsito", cuando en las vecindades del Estrecho haya una ruta de Alta Mar, como es el caso del Paso Drake.

Por otra parte, de las disposiciones de los Tratados anteriormente citados, se desprende inequívocamente que las facilidades de navegación que la República de Chile, en ejercicio de sus derechos soberanos, otorga a la República Argentina y a buques de terceras banderas se realiza por aguas interiores chilenas, por una ruta descrita en el Tratado de Paz y Amistad de 1984 y con las demás características y modalidades, especificadas en el Anexo No 2, aspectos esenciales del régimen de navegación establecidos por el citado Tratado.

\footnotetext{
23 Señala Remiro (1997) p. 639: “En líneas generales estos tratados aseguran la libre navegación por tales estrechos en términos similares a lo que hoy conocemos como paso en tránsito, si bien no se reconoce el derecho de sobrevuelo, insólito por lo demás en las fechas de su conclusión”.
} 
En consecuencia, por las razones precedentemente expuestas, no podemos estar de acuerdo con la opinión del profesor Hugo Caminos, quien al referirse al régimen que regula el paso de los buques por el Estrecho de Magallanes, señala: "The regime of transit as it now exists in the Straits of Magellan seems no different to that guaranteed by the 1982 Convention. Although Annex $N^{\circ} 2$ of the Treatry of Peace and Friendship outlines a more restrictive regime that transit passage (by limiting navigational routes to be used, requiring pilotage, prohibiting certain activities, and requiring submarines to navigate on the surface and show their flags), these restrictions apply only to Argentine and Chilean vessels navigating between certain ports in the Beagle Channel, in Antarctica and in other specified territorial waters" 24.

En este punto adquiere singular importancia el nuevo desarrollo del derecho internacional del mar el cual va unido con el régimen de paso en tránsito, el que tendrá que ser tomado en consideración al regular los usos adicionales de los estrechos que no fueron considerados en las convenciones internacionales de larga data, siendo este en opinión de la profesora María Teresa Infante un aspecto altamente controvertido y merecedor de algunas consideraciones. La primera, señala la profesora Infante, es que, "esos usos deben haber sido aceptados por el Estado o Estados costeros al estrecho en cuestión y, segundo, que exista una práctica reiterada mostrada por el Estado o Estados en cuestiones que han adaptado su conducta a los nuevos desarrollos"25.

La segunda consideración permite precisar que tanto la legislación nacional como la práctica de los Estados, en relación con los estrechos utilizados para la navegación internacional, es una cuestión difícil de establecer, en vista del continuo debate sobre si lo estipulado en la Convención de Naciones Unidas sobre el Derecho del Mar es resultado o no del desarrollo del derecho consuetudinario.

En torno a esta interrogante el propio profesor Francisco Orrego Vicuña, expresa que; "As a matter of fact, this debate is more doctrinal than practical, and hence little attention has been paid to practice as such and much to the process of formation of customary rules" agregando más adelante que "as it has happened with the exclusive economic zone and the continental shelf, one can recognize that the basic concept of transit passage might have become or is becoming a part of customary law but not so the specific conventional regime embodied in the 1982 Convention" 26.

Por su parte, Hugo Caminos, en su obra titulada, "The Legal Regime of Straits in the 1982 United Nations Convention on the Law of the Sea" al referirse a este tema señala que, "while States practice does not clearly present a pattern reflective of a generally accepted legal norm, it may be said that practice consistent with the transit passage regime of the 1982 Convention demonstrates that its provisions are well into the process of emerging as a regime of customary international law"27.

De esta forma, se puede concluir que la Parte III de la Convención de Naciones Unidad sobre el Derecho del Mar, en virtud de lo dispuesto en la letra c) del artículo 35,

${ }^{24}$ Caminos (1987) pp. 221-222.

25 INFANTE (1995) p. 185.

26 Orrego (1991) p. 367.

27 Caminos (1987) p. 231. 
no afecta al régimen jurídico del Estrecho de Magallanes, ya que su paso está regulado por convenciones internacionales de larga data y aun vigentes que se refieren específicamente a ese Estrecho, como el Tratado de Límites del año 1881, régimen que se reitera en el Tratado de Paz y Amistad del año 1984.

\section{LA CONSTRUCCIÓN DE TÚNELES Y PUENTES EN EL ESTRECHO DE MAGALLANES}

Un proyecto destinado a unir ambas riberas del Estrecho de Magallanes por medio de un túnel, un puente o ambos, no solo podría presentar dificultades técnicas sino que al mismo tiempo podría suscitar una serie de dificultades legales y ambientales, sobre todo tratándose de la primera hipótesis. De esta forma, similares problemas a los que a continuación serán analizados podría sufrir cualquier proyecto que tuviere como objetivo el construir un puente, un túnel o ambos, sobre un estrecho internacional como lo es el de Magallanes.

Sin perjuicio de lo anterior, es necesario hacer presente que en la actualidad algunos estrechos son cruzados por puentes o túneles como por ejemplo los puentes del Bosphorus 1 y 2 en Turquía, construidos en los años 1973 y 1988, son puentes colgantes que unen Europa y Asia o el puente Kanmon en Japón, así como el túnel del Canal de la Mancha "Channel Tunnel”, concluido en 1994, que une a Gran Bretaña y Francia, otro ejemplo en esta materia lo constituiría el Estrecho de Sound entre Dinamarca y Suecia, países que decidieron en 1995 construir la conexión "Oresund", compuesta de tres puentes y un túnel sobre el citado Estrecho.

No esta de más aclarar que ninguno de los puentes citados en los ejemplos anteriores ha pretendido, en todo caso, restringir la libertad de paso a través de dichos estrechos.

Si se analiza la zona geográfica del Estrecho de Magallanes en donde eventualmente se podría construir un puente, un túnel o ambos, debemos concluir como ya señaláramos anteriormente, que ambas riberas y sus aguas territoriales pertenecen en su integridad a Chile.

De este modo, Chile podría perfectamente fundamentar su intención de construir un puente o un túnel en la circunstancia que tanto los Tratados de Límites de 1881 y de Paz y Amistad de 1984 garantizan la libre navegación por el Estrecho de Magallanes y que este tipo de construcciones no restringirían en modo alguno tal libertad.

Sin embargo, es necesario tener presente que uno de los problemas más serios, y por consiguiente arduamente discutidos, que han sufrido los principales proyectos para construir un puente sobre un estrecho utilizado para la navegación internacional es el referido a la altura que deberían tener estos, con el objeto de permitir el paso de cualquier buque o nave bajo ellos. Para proceder a analizar este tema en particular, se hace indispensable volver a citar la circular que la Cancillería chilena hiciere llegar a los gobiernos amigos el 26 de octubre de 1873, relativa a la Declaración sobre Libertad de Navegación y sobre Neutralidad del Estrecho de Magallanes:

"Chile ha mantenido y mantiene la constante aspiración del inquebrantable deseo de que la navegación por los estrechos de Magallanes sea siempre franca y libre para todo 
el mundo, sin pretender sujetarla a otras gabelas o contribuciones que aquellas que sean indispensable al sostenimiento de los faros y de una inspección celosa para la completa seguridad y garantía de los navegantes. Mi gobierno desea, además, declarar la neutralización de los mismos estrechos, para el remoto e improbable evento de una guerra exterior, de manera que ni aún por tal circunstancia pudiera imponerse a las naves de todas las naciones otras limitaciones en su tránsito que las requeridas en tiempo de paz”.

Por su parte el tantas veces citado Artículo V del Tratado de Límites del año 1881, establece: "El Estrecho de Magallanes queda neutralizado a perpetuidad y asegurada su libre navegación para las banderas de todas las naciones. En el interés de asegurar esta libertad y neutralidad no se construirán en las costas fortificaciones ni defensas militares que puedan contrariar ese propósito".

Finalmente, los incisos $3^{\circ}, 4^{\circ}$ y $5^{\circ}$ del artículo 10 del Tratado de Paz y Amistad de 1984, prescriben lo siguiente:

"La soberanía de la República Argentina y la soberanía de la República de Chile sobre el mar, suelo y subsuelo se extenderán al Oriente y Occidente de dichos límites".

La delimitación aquí convenida en nada altera lo establecido en el Tratado de Límites de 1881, de acuerdo con el cual el Estrecho de Magallanes está neutralizado a perpetuidad y asegurada su libre navegación para las banderas de todas las naciones en los términos que señala su Artículo V".

"La República Argentina se obliga a mantener, en cualquier tiempo y circunstancias, el derecho de los buques de todas las banderas a navegar en forma expedita y sin obstáculos a través de sus aguas jurisdiccionales hacia y desde el Estrecho de Magallanes".

Como se puede apreciar en la circular que la Cancillería chilena emitiera en octubre de 1873, se utiliza el término "naves" y en el artículo 10, inciso 5\%, del Tratado de Paz y Amistad del año 1984 se utiliza el término "buques", en tanto que en el Artículo V del Tratado de 1881 a este respecto no se refiere explícitamente ni a naves ni buques ya que tan solo ocupa la frase "asegurada su libre navegación" del estrecho, "para las banderas de todas las naciones".

Al referirse estos instrumentos únicamente a naves o buques no se está calificando lo que el término significa o incluye. Sin perjuicio de lo anterior, habría que señalar que tanto los cruceros de lujo como los ferris estarían incluidos en las previsiones de los Tratados de 1881 y de 1984. Pero tal inclusión pareciera más cuestionable si se contemplan, por ejemplo, algunos tipos de unidades de extracción de petróleo. Por su parte, el Derecho Internacional entrega poca ayuda en esta materia pues no define los términos "buque" y "nave", los cuales son usualmente utilizados sin ser definidos, como ocurre por ejemplo en la Convención de Ginebra del Mar Territorial y la Zona Contigua de 1958, en la Convención de Ginebra sobre la Alta Mar de 1958, o la Convención de Naciones de Naciones Unidas sobre el Derecho del Mar de 1982.

En el caso relativo al paso por el Estrecho del Great Belt, suscitado entre Dinamarca y Finlandia el profesor Martti Koskenniemi señala que ambos países "acordaron que el Derecho Internacional no tenía una aplicación definitiva para definir barco (ship) y embarcación (vessel). La definición en los tratados marítimos internacionales ha sido hecha 
estrictamente para los propósitos de cada caso. Por esta razón, la práctica de los tratados conoce una amplia variedad de definiciones de barco" ${ }^{28}$.

Pese a lo señalado anteriormente, existen ciertas excepciones. Así, algunas Convenciones, especialmente las de la Organización Internacional del Trabajo, concernientes a los hombres de mar, relacionan el término "nave" con la navegación marítima. Otras convenciones adoptan un criterio más técnico al referirse al sistema de propulsión. Un tercer grupo, especialmente referido a la protección del medio ambiente marino, tiene una aproximación más amplia e incluye en la definición del término buque a cualquier objeto flotante o incluso a plataformas fijas. A este respecto el juez William L. Schachte Jr. señala que, "Es la perspectiva de los Estados Unidos que un buque en este contexto incluye cualquier nave con movimiento y que es capaz de propulsión propia y que esa propulsión es incidental a su propósito principal para el cual se utiliza normalmente" ${ }^{29}$.

La Convención de Naciones Unidas sobre el Derecho del Mar, en la Parte III relativa a los estrechos utilizados para la navegación internacional, no contempla entre sus preceptos la eventualidad de la construcción de puentes o túneles que atraviesen los estrechos. Los artículos relativos al paso en tránsito claramente prohíben a los Estados ribereños de un estrecho el obstaculizar dicho paso, por lo que la construcción de un puente que atraviese un estrecho utilizado para la navegación internacional podría según sus características constituir o no tal obstáculo.

En algunos casos, los problemas que un puente pudiese causar en la navegación internacional de los estrechos pueden llegar a impedirla absolutamente o con respecto a ciertos tipos de naves. Pero en otros casos, no se suscita problema alguno. Así, si el puente consistiere en una plataforma móvil, como lo sería un puente levadizo y con una anchura suficiente de la parte móvil el problema podría ni siquiera plantearse. Ello deberá a la vez compatibilizarse con los esquemas de separación de tráfico y con las consideraciones de tipo arbitral.

Como bien señala en esta materia el Sr. William L. Schachte Jr., refiriéndose al caso del Puente sobre el Estrecho del Great Belt, "Otro punto que habría que considerar tratándose de puentes, es el que se refiere a “¿cuál sería la altura suficiente, es decir, cuánta claridad vertical debería existir debajo de una plataforma fija?”, añadiendo que “¿debería ser lo suficientemente alta como para permitir a todos los buques que existan pasar bajo ella, o lo suficientemente alta como para permitir a todos los buques actualmente en construcción o en planificación de construcción el paso bajo ella, o aún más que eso, de forma tal de permitir el futuro paso de los diseños aún no contemplados?"30.

En este orden de ideas, se podría plantear la alternativa de que previa a la construcción de un puente sobre un estrecho, si hay problemas de interferencia con la navegación, debería consultarse a la Organización Marítima Internacional (OMI), asimilándolo al procedimiento de la consulta para el diseño de la separación del tráfico marítimo. Igualmente, el Estado ribereño debería dar publicidad a su proposición de construcción en forma pre-

\footnotetext{
${ }^{28}$ Koskenniemi (1996) p. 256.

29 Schachte (1992) p. 19.

30 Schachte (1992) p. 19
} 
via a llevarla a efecto. Sin embargo, en el caso del Estrecho de Magallanes esta alternativa no es procedente, pues una cosa es asegurar la libre navegación por el mismo y otra muy distinta es ceder la competencia para llevar a cabo actos de jurisdicción en las costas y en las aguas, suelo y subsuelo del estrecho, teniendo en consideración el respeto a la libre navegación conforme al régimen aplicable.

Cabe concluir que, si bien es cierto que los buques de terceras banderas gozan de la libre navegación por el Estrecho de Magallanes, no es menos cierto que un eventual proyecto de construcción de un puente sobre dicho estrecho, o de un túnel y un puente como en el caso de la "Conexión Oresund" compuesta de tres puentes y un túnel que unen a Dinamarca y Suecia, no se violaría derecho alguno si este permitiera el paso de todos los buques existentes en la actualidad, entendiéndose, asimismo, que este derecho solo cubre un tráfico normal y no se hace extensivo a estructuras anormales como lo serían plataformas petroleras o torres de perforación, toda vez que si así se entendiera se le estaría dando al concepto una extensión y naturaleza que no corresponde.

Tratándose de la construcción de túneles bajo el Estrecho de Magallanes, independiente de los problemas de ingeniería que esto pudiese generar, es preciso señalar que debe llegarse a idéntica conclusión que a la de los puentes, pues dicho tipo de construcciones no podría por su propia naturaleza obstruir el tráfico marítimo.

\section{CONCLUSIONES}

El Tratado de Límites de 1881 entre la República de Chile y la República Argentina, representó una transacción, por la que Chile cedió la Patagonia y Argentina renunció a sus pretensiones sobre el Estrecho de Magallanes. De esta forma, se abandonó el principio del uti possidetis en beneficio de un intercambio que satisfacía a los intereses de ambos países.

La República de Chile aceptó tres obligaciones respecto del Estrecho, las cuales se consignan en el artículo V, del citado Tratado: a) su libre navegación; b) su neutralización y c) la prohibición de construir fortificaciones.

En cuanto a la primera obligación, esta ya había sido declarada por Chile en el año 1873, mediante circular que la Cancillería chilena hiciera llegar a los gobiernos extranjeros con el objeto de proteger el comercio internacional y asegurar el uso inofensivo del Estrecho.

Asimismo, la República de Chile no renunció a su derecho de autodefensa ni a la protección de la seguridad de las naves que surcaran las aguas del Estrecho. Por ello, Chile ha dictado importantes Reglamentos, como el de Admisión y Permanencia de Naves Extranjeras y el de Pilotaje, en donde se exige un práctico para la navegación por el Estrecho de Magallanes y por los Canales Australes. Dichos Reglamentos encuentran su justificación en brindar seguridad a la navegación e impedir la contaminación pudiendo Chile, si lo estimare necesario, mantener, modificar o complementar su actual reglamentación.

Cabe indicar que respecto de las aguas del Estrecho de Magallanes, en razón del trazado de líneas de base rectas en sus costados laterales internos, quedaron ubicadas en la categoría de Mar Territorial. Y es sabido que en las aguas territoriales no procede el paso sumergido de submarinos, conforme a las reglas de la Convención de Ginebra de 1958 y a 
la Convención de Naciones Unidas sobre el Derecho del Mar. Por otro lado, las condiciones para la navegación de nuestros canales australes no son asimilables a las que se aplican en el Estrecho, ya que son consideradas para todos los efectos como aguas interiores.

En cuanto a la obligación de neutralización del Estrecho de Magallanes, esta solo afecta a Chile. Su objetivo es asegurar el comercio; proteger en tiempo de guerra el tráfico de neutrales y beligerantes, salvo en el caso que Chile estuviera en guerra; impedir que terceros ejecuten actos de guerra dentro del Estrecho y controlar el acceso y paso por este de naves durante el tiempo de guerra. Respecto de esta obligación la República Argentina no posee ningún control ya que el artículo $\mathrm{V}$ no se lo confiere.

En cuanto a la prohibición de construir fortificaciones en las costas, representa una obligación condicionada que no envuelve la indefensión del territorio chileno.

En virtud del artículo 10 del Tratado de Paz y Amistad de 1984, suscrito entre las Repúblicas de Chile y Argentina, se acuerda la línea de delimitación en el término oriental del Estrecho de Magallanes, determinada por Punta Dungeness en el Norte y Cabo del Espíritu Santo en el Sur, siendo el límite entre sus respectivas soberanías la línea recta que une el "Hito Ex Baliza Dungeness" situada en el extremo de dicho accidente geográfico y el "Hito I Cabo del Espíritu Santo" en Tierra del Fuego. Se conviene, asimismo, que esa delimitación en nada altera lo establecido en el Tratado de 1881. Por su parte, la República Argentina se obliga a mantener, en cualquier tiempo y circunstancia, el derecho de los buques de todas las banderas a navegar en forma expedita y sin obstáculos a través de sus aguas jurisdiccionales hacia y desde el Estrecho de Magallanes.

La Convención de Naciones Unidas sobre el Derecho del Mar regula en su Parte III los “Estrechos Utilizados para la Navegación Internacional”. Conforme a lo señalado en la letra c) del artículo 35 de esta Convención, las disposiciones de esa Parte no afectan el régimen jurídico del Estrecho de Magallanes, pues su paso está "regulado por convenciones internacionales de larga data y aún vigentes que se refieren específicamente a tales estrechos”, como el Tratado de Límites de 1881, régimen que se reitera en el Tratado de Paz y Amistad de 1984.

Chile ha manifestado en forma reiterada que la existencia del Tratado bilateral con Argentina sobre Límites del año 1881, cuyo artículo V está destinado específicamente a fijar el régimen de navegación del Estrecho de Magallanes, cual es el de "libre navegación", constituye precisamente un ejemplo claro del citado artículo 35 letra c) de la Convención. En efecto, se dan en él todos los requisitos que esta disposición exige: a) el ser un tratado internacional; b) de larga data; c) vigente en la actualidad; d) que en su artículo V se refiere específicamente a la navegación del Estrecho; y e) cuyo paso queda regulado en forma total por tiempo indefinido. Los términos del referido artículo V del Tratado de Límites de 1881, aunque son escuetos, definen perfectamente su uso.

Por consiguiente, frente al nuevo Derecho del Mar consagrado en la Convención indicada, el Estrecho de Magallanes queda exceptuado de la calificación de estrecho de paso en tránsito, aplicándose el Tratado de Límites de 1881 y el Tratado de Paz y Amistad de 1984, lo que implica a nuestro juicio las siguientes modalidades:

a) No existe libre vuelo sobre el Estrecho, como ocurre en el nuevo régimen de "Paso en Tránsito", el que, por otra parte, sería imposible en la práctica. 
b) No existe navegación sumergida de los submarinos u otros vehículos sumergibles a lo largo del Estrecho, sin olvidar que la caprichosa estructura de su fondo y las angosturas hacen peligroso su paso sumergido.

En relación con la factibilidad de construir túneles y/o puentes en el Estrecho de Magallanes, habría que señalar que si bien es cierto que los buques de terceras banderas gozan de la libre navegación por el Estrecho de Magallanes, no es menos cierto que un eventual proyecto de construcción de un puente y/o túnel sobre dicho Estrecho, no violaría derecho alguno si este permitiera el paso de todos los buques, entendiéndose que este derecho solo cubre un tráfico normal y no se hace extensivo a estructuras anormales como lo serían plataformas petroleras o torres de perforación, toda vez que si así se entendiera se le estaría dando al concepto una naturaleza y alcance que no corresponde.

\section{BIBLIOGRAFÍA CITADA}

Remiro, Antonio (1977): Derecho Internacional (Madrid, Edit. McGraw-Hill / Interamérica de España, S.A.U. España). 1269 p.

Alexandersson, Gunnar. (1982): The Baltic Straits (London, Martinus Nijhoff Publishers) pp. 74-95.

Benadava, Santiago (1989): Derecho Internacional Público (Santiago, Edit. Jurídica de Chile) pp. 240-243.

Benadava, Santiago (1993): Historia de las Fronteras de Chile (Santiago, Edit. Jurídica de Chile) pp. 47-64.

Bidau, Eduardo (1924): Derecho Internacional Público (Buenos Aires, Edit. Buenos Aires, Argentina) p. 168.

Caminos, Hugo (1987): The Legal Regime of Straits in the 1982 United Nations Convention on the Law of the Sea, en: Recueil des Cours: Vol. 205, pp. 221-222.

Cuyvers, Luc (1986): The Strait of Dover. (Lancaster, Martinus Nijhoff Publishers) pp. 47-77.

Escudero, Julio (1927): Situación Jurídica Internacional de las Aguas del Estrecho de Magallanes. (Santiago, Talleres de El Diario Ilustrado, Chile) 74 p.

Кон, Lion (1982): Straits in International Navigation (London, Oceana Publications). 171 p.

Koskenmiemi, Martti (1986): Case Concerning Passage Through the Great Belt. (Helsinki: University of Helsinki, Ocean Development \& International Law) pp. 255-289.

Lagos, Guillermo (1980): Historia de las Fronteras de Chile (Santiago, Edit. Andrés Bello, Chile) pp. 160-167.

Lagos, Guillermo (1985): La Delimitación Maritima Austral y el Tratado de Paz y Amistad entre Chile y Argentina (Santiago, Edit. Jurídica de Chile) 91 p.

Llanos, Hugo (1991): La Creación del Nuevo Derecho del Mar: el Aporte de Chile (Santiago Edit. Jurídica de Chile) 665 p.

Martinic, Mateo (1987): El Estrecho de Magallanes en el Tratado de Paz de 1984 en: Díaz, Rodrigo El Tratado de Paz y Amistad entre Chile y Argentina (Santiago, Edit. Universitaria, Chile) pp. 105-114. 


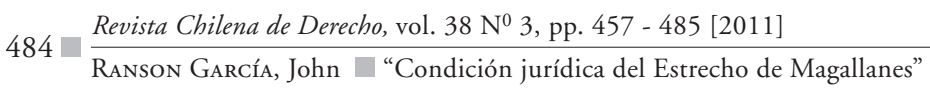

Morris, Michael (1988): The Strait of Magellan (London, Martinus Nijhoff Publishers) $198 \mathrm{p}$.

Orrego, Francisco (1991): States Practice and National Legislation. Law of the Sea at the Crossroads: The Continuing Search for a Universally Accepted Regime. (Berlín: Edited by Rüdiger Wolfrum, Duncker \& Humblot) pp. 367-371.

Pascal, Enrique (1986) Derecho Internacional Maritimo (Valparaíso, Imprenta de la Armada, Chile) 328 p.

Pelliza, Mario (1969): La Cuestión del Estrecho de Magallanes (Buenos Aires Eudeba Edit. Universitaria de Buenos Aires, Argentina) 305 p.

Prieto, Patricio (1987): El Régimen de Navegación por los Canales Australes, en Díaz, Rodrigo El Tratado de Paz y Amistad entre Chile y Argentina (Santiago, Edit. Universitaria, Chile) pp. 115-118.

Roch J. Ashley and SMITH Robert (1994): International Law Studies (Newport, Rhode Island, Naval War College, EE.UU.) pp. 177-229.

Schachte, William (1992) International Straits and Navigational Freedoms (The Law of the Sea: New Worlds, New Discoveries). Ed. E. Miles and T. Treves (Honolulu: Law of the Sea Institute, William S. Richardson School of Law, University of Hawaii) pp. $17-56$.

Storni, Segundo (1925): Mar Territorial. (Buenos Aires, Edit. Buenos Aires, Argentina) p. 40 .

Treves, Tullio (1990): Codification du Droit International et Pratique des Etats Dans le Droit de la Mer, en: Recueil des Cours, vol. 223 (1990-IV). (London, Martinues Nijhoff Publishers) pp. 124-137.

Wolfrum Rüdiger (1991): Law of the Sea at the Crossroads: The continuing Search for a Universally Accepted Regime. Veröffentlichungen des Instituts für Internationales Recht an der Universität Kiel. (Band 113). (Berlín. Duncker \& Humblot) 525 p.

\section{ARTÍCULOS EN DIARIOS Y REVISTAS}

Arnello Romo, Mario. "Significado de la Posición Geopolítica Austral Chilena. A 150 años de la Toma de Posesión del Estrecho de Magallanes", en: Estudios de la Revista Chilena de Geopolítica, vol. 9, N³, 1993, pp. 3-8.

Infante Caffi, María Teresa. "El Estrecho de Magallanes y su Régimen Jurídico”, en: Estudios, Sociedad Chilena de Derecho Internacional, 1983, pp. 49-69.

Infante Caffi, María Teresa. "Straits in Latin America: The Case of the Strait of Magellan” Ocean Development \& International Law, vol. 26, 1995, pp. 175-185.

Martinic, Mateo. "Estrecho de Magallanes, Territorio Marítimo Chileno, Punta Arenas Magallanes. Chile”, en: Anales del Instituto de la Patagonia, Vol. XII, 1981, pp. 7-40.

Mc Caffrey, Stephen, "The International Law Commission Adopts Draft Articles on International Watercourse", en: American Journal of International Law, vol. 89, 1995, pp. 395-403. 
Paravic Valdivia, Sergio "La Boca Oriental del Estrecho de Magallanes", Santiago, Chile: Instituto de Investigaciones del Patrimonio Territorial de Chile, Universidad de Santiago, 1986, pp. 15-84. (Colección Terra Nostra: 8).

Pascal García-Huidobro, Enrique. “Dominio Chileno del Estrecho de Magallanes”, en: El Mercurio, domingo 2 de diciembre de 1979, pp. D8 - D9.

Vio Valdivieso, Fabio. "Límites Marítimos de Chile”, en: Memorial del Ejército 1976, pp. 33-56.

\section{NORMAS CITADAS}

Tratado de Límites de 1881, suscrito por las Repúblicas de Chile y Argentina. Tratado de Paz y Amistad de 1984, suscrito por las Repúblicas de Chile y Argentina. Convención de Naciones Unidas sobre el Derecho del Mar de 1982. 
